\title{
Improving Medication Adherence and Health Care Outcomes in a Commercial Population through a Community Pharmacy
}

\author{
Osayi E. Akinbosoye, PhD, PAHM, Michael S. Taitel, PhD, James Grana, PhD, \\ Jerrold Hill, $\mathrm{PhD}$, and Rolin L Wade, RPh, $\mathrm{MS}^{2}$
}

\begin{abstract}
The aim was to evaluate the impact of a multifaceted set of medication management interventions offered by a community pharmacy on adherence, health care utilization, and costs within a commercial population. Patients initiating therapy within 16 drug classes from February 7, 2013, to October 6, 2013, were offered various adherence interventions by Walgreens pharmacy. Patients were linked deterministically to IMS medical and prescription databases for 6-month pre- and post-index data analysis. Walgreens patients (intervention) were matched to patients using other pharmacies (control) on drug class, index date, baseline demographics, clinical factors, utilization, and costs. Outcomes were evaluated at the intent-to-treat level using post-index differences and generalized estimating equations (GEE) regression model. Paired $t$ tests (continuous variables) and McNemar's test (dichotomous variables) were used to determine the significance of estimated model coefficients at $\alpha=0.05$. The groups ( $\mathrm{n}=72,410$ each) had similar age ( 47.1 vs. 45.7 years), sex $(41.2 \%$ vs. $40.2 \%$ male), and disease burden ( 0.52 vs. 0.40 mean Charlson comorbidity index). In the 6-month post-index period, the intervention group had 3.0\% greater medication adherence, $1.8 \%$ fewer hospital admissions, $2.7 \%$ fewer emergency room (ER) visits, and 0.53 fewer mean outpatient visits compared to the control group (all $P<0.0001)$. The intervention group incurred significantly lower GEE-adjusted pharmacy costs $(-\$ 92)$, outpatient costs $(-\$ 120)$, ER costs $(-\$ 38)$, and total health care costs $(-\$ 226.07)$ (all $P<0.0001)$, and higher inpatient costs $(\$ 86, P<0.004)$ per patient. A multifaceted set of medication management interventions offered by a community pharmacy were associated with patients in a commercial population having significantly higher medication adherence and lower health care utilization and costs.
\end{abstract}

\section{Introduction}

$\mathbf{N}$ ONADHERENCE TO MEDICATION is associated with increased hospitalization, progression of disease, and higher mortality. ${ }^{1,2}$ However, only about $50 \%$ of patients with chronic conditions take their medications as prescribed., Research has demonstrated that adherence can lead to lower health care utilization and total costs, ${ }^{5,6}$ and is associated with better health outcomes and decreased risk of hospitalization. ${ }^{6,7}$

Factors associated with nonadherence are complex and generally fall under the following categories: patient-related factors, health care system factors, condition-related factors, and therapy-related factors. ${ }^{8,9}$ Patient-related factors can be subdivided into demographic, socioeconomic, cultural, and behavioral factors. ${ }^{10}$ The most commonly reported patientrelated reasons for nonadherence are forgetfulness and perception about side effects and drug efficacy ${ }^{11}$; for example, interventions that incorporate pharmacist counseling, patient education, and reminder systems have been shown to improve medication adherence. ${ }^{1,12-14}$

Pharmacist counseling is important because although a patient's physician has a role to play in the patient's adherence to medications as prescribed, ${ }^{15}$ from the health care system standpoint, the physician's ability to identify nonadherence is limited. ${ }^{16}$ Community pharmacists are uniquely positioned to help mitigate the high risk of medication discontinuation and improve adherence for patients initiating therapy ${ }^{14}$ because of their access to prescription refill information and frequent

\footnotetext{
${ }^{1}$ Walgreen Co., Health Analysis Research and Reporting, Deerfield, Illinois.

${ }^{2}$ IMS Health, Health Economics and Outcomes Research, Real World Solutions, Plymouth Meeting, Pennsylvania.

(C) Akinboyse et al. 2016; Published by Mary Ann Liebert, Inc. This Open Access article is distributed under the terms of the Creative Commons Attribution Noncommerical License (http://creativecommons.org/licenses/by-nc/4.0/) which permits any noncommercial use, distribution, and reproduction in any medium, provided the original author(s) and the source are credited.
} 
interactions with patients. Moreover, research has demonstrated that pharmacist-delivered interventions improve adherence to medications and clinical outcomes such as blood pressure, blood glucose, blood lipids, and cardiovascular risk factors. ${ }^{17-19}$ However, the majority of pharmacist-delivered interventions to address nonadherence have focused on either (1) the socioeconomic and cultural aspects (ie, knowledge, attitudes, medication beliefs $)^{20,21}$ or (2) the behavioral aspect (ie, forgetfulness, lack of self-efficacy). ${ }^{22,23}$ No known study has examined the impact of comprehensive interventions comprising pharmacist counseling, medication therapy management (MTM), and omni-channel sets of refill reminders on medication adherence, perhaps because of the substantial costs associated with such interventions.

Throughout its long history, Walgreens has implemented various adherence programs in its more than 8100 locations in the United States. The programs - proactive and reactivewere designed to address the following reasons for nonadherence: (1) socioeconomic and cultural (ie, knowledge, attitudes, medication beliefs); (2) behavioral (ie, forgetfulness, self-efficacy); and (3) provider (ie, communication, relationship with patient). For new-to-therapy patients, these programs include pharmacist-initiated calls and consultations; for patients continuing therapy, they include MTM consultations, automated refill reminders, pickup reminders, and late-to-refill reminders or face-to-face consultations. The overarching goal of these programs is to help patients get and stay on their medications while enhancing their experience by incorporating convenience and improved satisfaction. Thus, the objective of this study was to evaluate the impact of this multifaceted set of interventions on adherence, health care utilization, and health care costs.

\section{Methods}

Patients initiating therapy within 16 drug classes were offered various adherence interventions by a community pharmacy between February 7, 2013, and October 6, 2013. Targeted drug classes included antianginal agents, antiasthmatic and bronchodilator agents, anticoagulants, antidepressants, oral antidiabetics, antihyperlipidemics, antihypertensives, antiparkinson agents, beta-blockers, calcium channel blockers, cardiotonics, diuretics, endocrine and metabolic agents-misc., genitourinary agents-misc., hematological agents-misc., and thyroid agents. These drug classes were selected because they represented approximately $70 \%$ of the community pharmacy's prescription fills across all maintenance drug classes for chronic conditions management, and were thought to be clinically amenable to pharmacist intervention.

New-to-therapy patients, identified by the pharmacy system, were eligible to receive an initial pharmacist consultation that could be conducted at the point of sale, when patients picked up their new medication, or over the phone within 3 days of prescription pickup. During the initial consultation, whether conducted face-to-face or over the phone, the pharmacist utilized motivational interviewing technique to determine the patient's confidence and commitment to following the prescribed treatment regimen, address any questions and/or concerns the patient might have, and discuss fitting medications into the patient's daily routine. Patients who completed the initial counseling session, and were not excluded because of self-report of prior use of a medication within the same drug class, were eligible for a follow-up counseling session to be completed at their second fill. The second counseling session reinforced messages from the first; the pharmacist inquired about the patient's experience during the first period of treatment and focused on removing any barriers to adherence. On average, the first consultation lasted 3 to 5 minutes, and follow-up consultations were 1 to 2 minutes in length.

Patients eligible for the new-to-therapy consultations had the opportunity to participate in other adherence programs available to patients on chronic maintenance medications. Pickup and refill reminders were proactive tools that motivated members to get their filled prescriptions, whereas late-to-refill consultations and reminders were reactive tools aimed to get patients back on track after a missed refill opportunity. Some patients also were eligible for MTM consultations aimed to address issues arising from polypharmacy, preventable adverse drug events, and inappropriate use of medication.

\section{Data sources and patient selection}

This retrospective cohort analysis was conducted using a data extract comprised of: (1) the Walgreens community pharmacy's adherence program data; (2) IMS longitudinal $\mathrm{Rx}$ open-source claims data (LRx) for identification of this pharmacy's patients with no exposure to other pharmacies (intervention group), and patients of other pharmacies with no exposure to the intervention pharmacy, initiating therapy under any of the 16 drug classes within \pm 30 days of the index period between February 7, 2013, and October 6, 2013 (control group); and (3) IMS PharMetrics Plus (PMTX+) data for outcomes measurement-adherence, utilization, and cost - and other demographic and clinical variables needed for matching. The PMTX+ database represents the most comprehensive and diverse commercial health plan claims and eligibility database in the United States, covering all US geographies, settings of care, and therapeutic drug areas.

Patients in the intervention group were linked deterministically to the PMTX+ and LRx databases so that pharmacy and medical claims data could be analyzed for patients with at least 6 months of pre- and post-index continuous eligibility. A patient's drug class-specific index date was defined as the date of the first prescription fill for a medication within that drug class. The control group was matched to the intervention group using a combination of exact and propensity score matching to ensure balance in terms of quantifiable factors that affect the outcomes of interest and, as such, mitigate selection bias. The exact match was based on each of the 16 drug classes, index period-4 index periods in 2013 were used: February and March, April and May, June and July, and August, September, and October; and matched pairs were required to have an index date within the same index period-and geographic region. The propensity score matching included a 1:1 greedy algorithm without replacement, with a caliper of \pm 0.1 standard deviation. Variables used for the propensity score matching included age groups, sex, health plan type, pre-index total costs, out-of-pocket cost for the index prescription filled, unique count of drug classes within which the patient had a prescription filled, pre-index 30-day adjusted fill rate, preindex generic dispensing rate, and pre-index comorbidities. Balance between the intervention and control groups was 
assessed using standardized differences of $\leq 0.1^{24}$ in means or proportion.

\section{Outcomes assessment}

Study outcomes included medication adherence, health care utilization, and health care costs. Medication adherence was measured using pharmacy claims data. Adherence at the drug class level was quantified using proportion of days covered (PDC), calculated as the number of days with medication(s) within the same drug class on hand divided by 183 days. Overall patient-level adherence was quantified using days' supply-weighted PDC across all drug classes utilized. Patients were considered adherent if their PDC was $\geq 80 \%$, a commonly used threshold to define adherence. ${ }^{25}$

Health care utilization and costs were assessed using several components of medical and pharmacy claims data-inpatient, outpatient, and emergency department. Utilization was quantified using proportion of patients with $\geq 1$ hospital admissions, number of inpatient hospital stays, total inpatient days, total outpatient visits, proportion of patients with $\geq 1$ emergency room visits, total emergency room visits, total number of prescriptions filled, total number of unique drug classes for prescriptions filled, 30-day adjusted fill rate, and generic dispensing rate. Health care costs per patient were quantified using pharmacy cost, medical cost (ie, inpatient costs, outpatient costs, emergency department costs), and total health care costs (ie, the sum of pharmacy and medical costs). Costs were calculated using allowed dollar amounts, the discounted amounts negotiated by the health plans with physicians, hospitals, and other health care providers in their networks.

\section{Statistical analysis}

Outcomes were compared between the intervention and control groups at the intent-to-treat level. Descriptive analysis included assessment of 6-month pre-index differences in demographic characteristics, clinical factors, health care utilization, and costs between the intervention and control groups. Unadjusted program effects were assessed using differences in outcomes-adherence, health care utilization, and costs-between the intervention and control groups at the 6-month post-index period.

Generalized estimating equations (GEE) model with unstructured correlation matrix was used to control for extraneous confounders, adjust for persisting imbalance in some variables after propensity score matching, and improve the validity of estimated program effects. This multivariable regression modeling approach to paired data is commonly used for improved adjustment of prognostic covariates and estimated treatment effects. ${ }^{26-28}$ The GEE model accounts for clustered or correlated outcomes-a likely occurrence with repeated measures and matched observations-in addition to nonlinearities of covariates and correlated error terms. The repeated measures-hence correlated nature of observations-stem from the likelihood that the same patient may be new to therapy under multiple drug classes of interest. The GEE estimates are robust to the specification of the correlation matrix, and are consistent under mild regularity conditions. ${ }^{29}$ All analyses were conducted in SAS version 9.3 (SAS Institute Inc., Cary, North Carolina); paired $t$ tests for continuous variables and McNemar's test for dichotomous variables were used to determine the significance of estimated model coefficients at $\alpha=0.05$.

\section{Results}

A total of 4,378,857 intervention patients initiated therapy within the 16 drug classes, and of these, 2,512,748 (57.4\%) patients completed at least 1 pharmacist consultation. The study sample attrition by reason is presented in Table 1 . Overall, a total of 528,466 patients $(99,977$ intervention patients and 428,489 control patients) met the inclusion criteria for the initial samples included in the study. These samples were used for the assessment of baseline differences and subsequent matchings (exact and propensity score).

There were significant differences between the intervention and control groups across all of the evaluated baseline demographics, clinical characteristics, and baseline health care utilization and costs. Patients in the intervention group were significantly older (mean age: 48 vs. 39 years;

Table 1. Study Sample Attrition, by Reason

\begin{tabular}{|c|c|c|}
\hline Reason & Intervention, $N(\%)$ & Control, $N(\%)$ \\
\hline Number of intervention patient IDs received by IMS & $4,378,857(100 \%)$ & \\
\hline Intervention patient IDs with a match to IMS ID & $4,370,391(99.8 \%)$ & \\
\hline Intervention patient IDs with a link to PMTX+ & $438,520(10 \%)$ & \\
\hline $\begin{array}{l}\text { Control patients initiating therapy within } \\
\text { the } 16 \text { drug classes of interest }\end{array}$ & & $1,084,338(100 \%)$ \\
\hline $\begin{array}{l}\text { Continuous observation in the PMTX+ database } \\
\text { for a minimum of } 6 \text { months prior to the index date }\end{array}$ & $189,928(43.3 \%)$ & $615,900(56.8 \%)$ \\
\hline $\begin{array}{l}\text { Continuous observation in the PMTX+ database } \\
\text { for a minimum of } 6 \text { months post the index date }\end{array}$ & $157,784(83.1 \%)$ & $525,236(85.3 \%)$ \\
\hline $\begin{array}{l}\text { Has at least } 1 \mathrm{RX} \text { claim post index and no extreme } \\
\text { pre/post index total cost above mean }+5^{*} \mathrm{SD}\end{array}$ & $112,319(71.2 \%)$ & $482,955(92 \%)$ \\
\hline $\begin{array}{l}\text { Has at least } 1 \text { index drug claim within }+/-30 \text { days } \\
\text { of index date in the PMTX+ database }\end{array}$ & $101,212(90.1 \%)$ & $434,605(90 \%)$ \\
\hline $\begin{array}{l}\text { Has no extreme OOP for index script beyond the } \\
\text { average } 99 \% \text { percentile of intervention and control patients }\end{array}$ & 99,977 (98.8\%) & $431,127(99.2 \%)$ \\
\hline Has no patient ID within intervention patients cohort & & $428,489(99.4 \%)$ \\
\hline Control patients matched to intervention patients & $72,410(72.4 \%)$ & $72,410(16.9 \%)$ \\
\hline
\end{tabular}

$\mathrm{ID}=$ identification; $\mathrm{OOP}=$ out of pocket cost $\mathrm{PMTX}+=$ PharMetrics Plus; $\mathrm{Rx}=$ prescription; $\mathrm{SD}=$ standard deviation . 
$\mathrm{p}<0.0001$ ) and sicker (mean Charlson comorbidity index [CCI] score: 0.60 vs. $0.31 ; P<0.0001)$ compared to patients in the control group. Baseline treatment utilization (hospital admission, inpatient hospital stays and days, outpatient visits, emergency room visits, total number of prescriptions, number of unique drug classes for prescriptions filled, 30day adjusted fill rate, and generic dispensing rate) and costs (total health care, pharmacy, inpatient, outpatient, and emergency room) were significantly higher for the intervention group compared to control.

The exact and propensity score matching led to a final sample of 72,410 matched pairs used for subsequent assessment of postindex outcomes and program effects. Table 2 contains descriptive statistics for the post-match intervention and control groups $(\mathrm{n}=72,410$ each). Results show groups were well matched on many baseline characteristics of interest. But some significant differences remained (standardized differences $>0.1$ ) among the matched samples with respect to age, health plan type, certain comorbidities of interest, mean CCI score, emergency room visits, mean total number of prescriptions, mean number of unique drug classes for prescriptions filled, mean 30-day adjusted fill rate, and mean generic dispensing rate. These differences warranted that adjustments be made using the GEE regressions model to further mitigate potential biases.

Unadjusted overall adherence and utilization statistics in the 6-month post-index period are presented in Table 3. The proportion of patients adherent (PDC $\geq 80 \%$ ) during this period was significantly higher in the intervention group compared to control (difference $=2.0 \%, P<0.0001$ ). Un- adjusted overall mean PDC also was significantly higher for the intervention group compared to control (difference $=0.030, P<0.0001)$. Unadjusted drug class-specific mean PDC was significantly higher in the intervention group for antiasthmatic and bronchodilator agents, antidepressants, diuretics, and genitourinary agents (Fig. 1).

Unadjusted health care utilization in the 6-month postindex period was significantly lower in the intervention group compared to the control group across all the domains evaluated. Table 4 shows results of unadjusted health care costs during the same 6-month period. A nonsignificant difference was observed in total unadjusted health care costs between the intervention and control groups (difference $=\$ 16, P=0.7659)$. Lower medical costs in the control group (difference $=-\$ 117, P=0.0107$ ) were offset by higher prescription (difference $=\$ 133, P<0.0001$ ) and inpatient costs (difference $=\$ 94, P=0.002$ ).

Table 5 shows results of the regressions analysis using GEE models. Adjusted PDC was significantly higher for the intervention group compared to control (difference $=0.018$, $P<0.0001)$. After adjusting for baseline differences, probability of being adherent (PDC $\geq 80 \%$ ) in the intervention group was 1.04 times that of the control group $(P=0.001)$. Adjusted health care utilization in the 6-month post-index period was significantly lower in the intervention group compared to control. (Mean number of prescription fills: 15.10 vs. 17.56 ; difference $=-2.46, P<0.0001$; hospital days: 0.33 vs. 0.40 ; difference $=-0.07, P<0.0001$; outpatient visits: 7.53 vs. 8.27 ; difference $=-0.74, P<0.0001$;

Table 2. Baseline Demographic Characteristics of the Study Groups (Post Match)

\begin{tabular}{|c|c|c|c|c|}
\hline Baseline characteristics & $\begin{array}{l}\text { Intervention } \\
(n=72,410)\end{array}$ & $\begin{array}{c}\text { Control } \\
(n=72,410)\end{array}$ & $\mathrm{P}$ value & $\begin{array}{c}\text { Standardized } \\
\text { difference }(¥)\end{array}$ \\
\hline \multicolumn{5}{|l|}{ Age at index (years) } \\
\hline Mean (Standard deviation) & $47.1(13.3)$ & $45.7(13.5)$ & $<.0001$ & 0.107 \\
\hline 95\% Confidence interval & {$[47.0-47.2]$} & {$[45.6-45.8]$} & & \\
\hline \multicolumn{5}{|l|}{ Sex at index: $\mathrm{n}(\%)$} \\
\hline Male & $29,816(41.2 \%)$ & $29,133(40.2 \%)$ & 0.0003 & 0.019 \\
\hline \multicolumn{5}{|l|}{ Health plan type at index: $n(\%)$} \\
\hline Health maintenance organization & $4109(5.7 \%)$ & $1589(2.2 \%)$ & $<.0001$ & 0.180 \\
\hline Preferred provider organization & $63,660(87.9 \%)$ & $67,870(93.7 \%)$ & $<.0001$ & -0.202 \\
\hline All others & $4641(6.4 \%)$ & $2951(4.1 \%)$ & $<.0001$ & 0.105 \\
\hline \multicolumn{5}{|l|}{ Primary payer type at index: $n(\%)$} \\
\hline Commercial & $41,165(56.8 \%)$ & $40,085(55.4 \%)$ & $<.0001$ & 0.030 \\
\hline Medicaid & $574(0.8 \%)$ & $774(1.1 \%)$ & $<.0001$ & -0.029 \\
\hline Medicare & $528(0.7 \%)$ & $131(0.2 \%)$ & $<.0001$ & 0.082 \\
\hline Self-Insured & $30,143(41.6 \%)$ & $31,420(43.4 \%)$ & $<.0001$ & -0.036 \\
\hline \multicolumn{5}{|l|}{ Comorbidities: n (\%) } \\
\hline Diabetes mellitus & $7677(10.6 \%)$ & $4804(6.6 \%)$ & $<.0001$ & 0.142 \\
\hline Dyslipidemia & $19,250(26.6 \%)$ & $15,175(21 \%)$ & $<.0001$ & 0.132 \\
\hline Hypertension & $21,973(30.3 \%)$ & $17,856(24.7 \%)$ & $<.0001$ & 0.128 \\
\hline Thyroid disease & $6351(8.8 \%)$ & $4154(5.7 \%)$ & $<.0001$ & 0.117 \\
\hline Mean Charlson comorbidity index score & 0.52 & 0.40 & $<.0001$ & 0.119 \\
\hline Patients with $\geq 1$ emergency room visit & $11,773(16.3 \%)$ & $14,678(20.3 \%)$ & $<.0001$ & -0.104 \\
\hline Mean total number of prescriptions & 11.97 & 10.33 & $<.0001$ & 0.156 \\
\hline $\begin{array}{l}\text { Mean number of unique } \\
\text { drug classes for prescriptions filled }\end{array}$ & 5.64 & 5.14 & $<.0001$ & 0.135 \\
\hline Mean 30-day adjusted fill rate & 13.06 & 11.01 & $<.0001$ & 0.161 \\
\hline Mean generic dispensing rate & 0.76 & 0.80 & $<.0001$ & -0.138 \\
\hline
\end{tabular}

$¥:$ Standardized differences were used to assess balance between groups across variables. Balance was determined for differences $\leq 0.1$. 
Table 3. Unadjusted Overall Adherence and Utilization in the 6-Month Post-Index Period

\begin{tabular}{|c|c|c|c|}
\hline Measure & Intervention $(n=72,410)$ & Control $(n=72,410)$ & $\mathrm{P}$ value \\
\hline \multicolumn{4}{|l|}{ Adherence } \\
\hline Mean (standard deviation) & $0.552(0.334)$ & $0.522(0.335)$ & \multirow[t]{2}{*}{$<.0001$} \\
\hline $95 \%$ confidence interval & {$[0.550-0.555]$} & {$[0.520-0.555]$} & \\
\hline Adherent (PDC $\geq 80 \%)$ : n (\%) & $24,830(34.3 \%)$ & $23,402(32.3 \%)$ & $<.0001$ \\
\hline Patients with $\geq 1$ hospital admission: $\mathrm{n}(\%)$ & $3591(5.0 \%)$ & $4907(6.8 \%)$ & $<.0001$ \\
\hline \multicolumn{4}{|l|}{ Inpatient hospital stays } \\
\hline Mean (standard deviation) & $0.06(0.31)$ & $0.08(0.35)$ & \multirow[t]{2}{*}{$<.0001$} \\
\hline $95 \%$ confidence interval & {$[0.06-0.06]$} & {$[0.08-0.09]$} & \\
\hline \multicolumn{4}{|l|}{ Total inpatient days } \\
\hline Mean (standard deviation) & $0.33(2.68)$ & $0.42(2.89)$ & \multirow[t]{2}{*}{$<.0001$} \\
\hline $95 \%$ confidence interval & {$[0.31-0.35]$} & {$[0.4-0.44]$} & \\
\hline \multicolumn{4}{|l|}{ Total outpatient visits } \\
\hline Mean (standard deviation) & $7.62(9.30)$ & $8.15(9.07)$ & \multirow[t]{2}{*}{$<.0001$} \\
\hline $95 \%$ confidence interval & {$[7.55-7.68]$} & [8.08-8.22] & \\
\hline Patients with $\geq 1$ ER visit: $n(\%)$ & $9167(12.7 \%)$ & $11,132(15.4 \%)$ & $<.0001$ \\
\hline \multicolumn{4}{|l|}{ Total ER visits } \\
\hline Mean (standard deviation) & $0.19(0.64)$ & $0.23(0.74)$ & \multirow[t]{2}{*}{$<.0001$} \\
\hline $95 \%$ confidence interval & {$[0.18-0.19]$} & {$[0.23-0.24]$} & \\
\hline
\end{tabular}

$\mathrm{ER}=$ emergency room; $\mathrm{PDC}=$ proportion of days covered.

emergency room visits: 0.18 vs. 0.23 , difference $=-0.05$, $P<0.0001)$. Adjusted total health care cost was significantly lower for the intervention group compared to control (difference $=\$ 226, P<0.0001)$. Significant cost savings were observed in the intervention group across all cost categories evaluated, except for inpatient costs (difference $=\$ 86$, $P<0.0001)$. Furthermore, the 6 -month adjusted cost savings summed across pharmacy, inpatient, outpatient, and emer- gency department costs was $\$ 164$ per patient-a $3.0 \%$ reduction for the intervention group compared to control.

\section{Discussion}

Previous studies on the relationship between adherence and health care utilization and costs have demonstrated that higher adherence is associated with reductions in health care

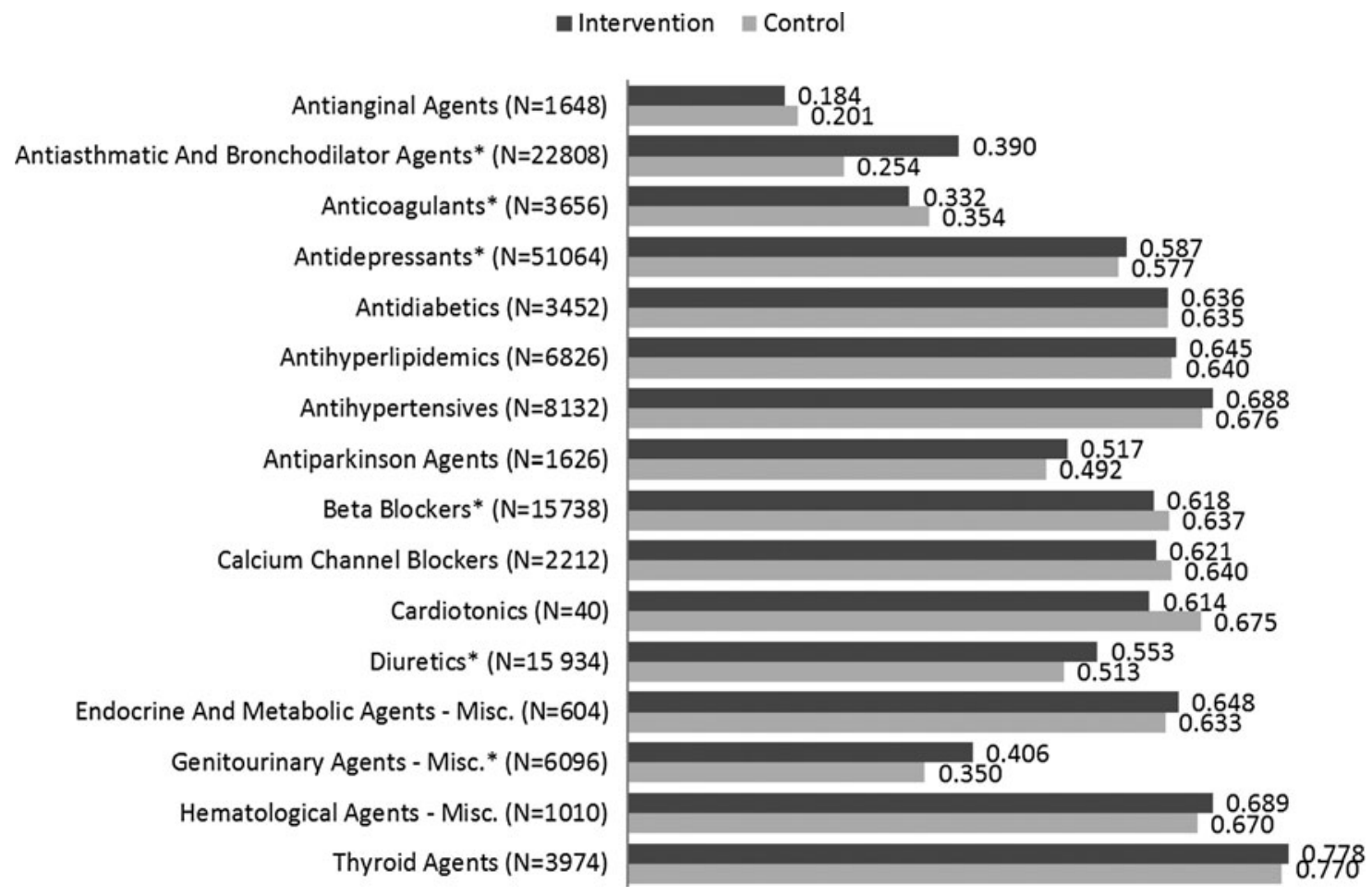

FIG. 1. Unadjusted drug class-specific adherence (mean proportion of days covered) in the 6-month post-index period. The Ns represent total patient counts for intervention and control groups.

* denotes significant difference between intervention and control groups at $\alpha=0.05$. 
Table 4. Unadjusted Health Care Costs in the 6-Month Post-Index Period

\begin{tabular}{lccc}
\hline Measure & Intervention $(n=72,410)$ & Control $(n=72,410)$ & P value \\
\hline $\begin{array}{l}\text { Total health care costs per person } \\
\text { Mean (standard deviation) }\end{array}$ & $5155.59(10,908.06)$ & $5139.61(9463.39)$ & 0.7659 \\
95\% confidence interval & {$[5076.14-5235.05]$} & {$[5070.68-5208.54]$} & \\
$\begin{array}{l}\text { Total medical costs per person } \\
\text { Mean (standard deviation) }\end{array}$ & $3744.53(9271.42)$ & $3861.93(8203.22)$ & 0.0107 \\
95\% confidence interval & {$[3677.00-3812.06]$} & {$[3802.18-3921.68]$} & \\
Total pharmacy costs per person & & & \\
Mean (standard deviation) & $1411.06(4187.12)$ & $1277.68(3503.74)$ & $<.0001$ \\
95\% confidence interval & {$[1380.56-1441.56]$} & {$[1252.16-1303.20]$} & \\
$\begin{array}{l}\text { Total inpatient costs per person } \\
\text { Mean (standard deviation) }\end{array}$ & $1041.27(6279.10)$ & $947.3(5237.57)$ & 0.002 \\
95\% confidence interval & {$[995.54-1087.01]$} & {$[909.15-985.45]$} & $<.0001$ \\
Total outpatient costs per person & $2557.31(5544.25)$ & $2724.92(5283.01)$ & \\
$\begin{array}{l}\text { Mean (standard deviation) } \\
\text { 95\% confidence interval }\end{array}$ & {$[2516.93-2597.69]$} & {$[2686.44-2763.40]$} & \\
Total emergency room costs per person & & $189.71(901.67)$ & $<.0001$ \\
Mean (standard deviation) & $145.95(740.80)$ & {$[183.14-196.28]$} & \\
95\% confidence interval & {$[140.55-151.34]$} & & \\
\hline
\end{tabular}

utilization and costs. ${ }^{5,30}$ In the present study, this relationship was assessed for patients initiating therapy within 16 drug classes, using a large US commercial health plan claims and eligibility database. New-to-therapy patients engaged in a variety of adherence programs offered by a large US community pharmacy were compared to similar patients of other US pharmacies.

Study results showed that overall unadjusted medication adherence was significantly higher by $3 \%$, with total costs not significantly different in the intervention group compared to control. All measures of unadjusted utilization and costs, except inpatient and pharmacy costs, were significantly lower for the intervention group compared to control. Results of the adjusted model also showed adherence was significantly higher by $1.8 \%$; and all measures of cost, except for inpatient, were significantly lower with a significant 6-month total health care cost reduction of $\$ 226.07$ per patient in the intervention group compared to control.

Based on the study results, an actuarial model was developed to estimate the per-member-per-month (PMPM) savings in a theoretical commercial health plan population of 1 million members. Key assumptions of the model included the community pharmacy's market share, its estimate of members expected to be new to therapy under any of the 16 targeted drug classes based on the community pharmacy's own data, number of members expected to utilize any medication over a 1-year measurement period based on research evidence, ${ }^{31}$ and National Health Expenditure's average gross annual health plan costs. The model used inflation indexes from the United States $\mathrm{Bu}$ reau of Labor Statistics to adjust cost estimates from this study, and other cost parameters from earlier years, to 2015 levels. The estimated savings associated with the community pharmacy's multifaceted set of adherence interventions-based on the assumptions that its share of the health plan's member population will range from $15 \%$ to $35 \%, 29 \%$ of its members will be new to therapy under any of the 16 targeted drug classes, and $68.1 \%$ of its members will utilize medications for treatment of chronic and acute health issues in 2015-ranged from $\$ 0.58$ to \$1.57 PMPM.

Questions might arise as to why the adjusted pharmacy cost was lower in the intervention group when adherence

Table 5. Regressions-Adjusted Overall Adherence and Health Care Costs in the 6-Month Post-Index Period

\begin{tabular}{lcccc}
\hline & Intervention $(n=72,410)$ & Control $(n=72,410)$ & Difference & P value \\
\hline $\begin{array}{l}\text { Adherence (PDC) } \\
\text { Probability of adherent }\end{array}$ & 0.546 & 0.528 & 0.018 & $<.0001$ \\
& $\mathbf{P D C} \geq \mathbf{8 0 \%})$ : intervention vs. control & & & \\
& Odds ratio & $\mathbf{9 5 \%}$ confidence interval & $\boldsymbol{P}$ value \\
& 1.040 & 1.015 & 1.065 & 0.001 \\
Total health care costs & Intervention $(\mathbf{n}=\mathbf{7 2 , 4 1 0})$ & Control $(\mathbf{n}=\mathbf{7 2 , 4 1 0})$ & Difference & $\boldsymbol{P}$ value \\
Pharmacy costs & 5084.88 & 5310.95 & -226.07 & $<.0001$ \\
Inpatient costs & 1458.75 & 1550.97 & -92.22 & $<.0001$ \\
Outpatient costs & 1035.48 & 949.39 & 86.09 & 0.004 \\
Emergency room costs & 2706.43 & 2826.44 & -120.01 & $<.0001$ \\
\hline
\end{tabular}

$\mathrm{PDC}=$ proportion of days covered. 
was higher. It is important to note that although adherence measures were only specific to the 16 targeted drug classes of interest, pharmacy costs were for all medications utilized. The drug class-specific adherence results show the intervention group had significantly higher adherence to antiasthmatic and bronchodilator agents compared to control (Fig. $1 ; \mathrm{PDC}=0.39$ vs. $0.25, P<0.001$ ). For conditions such as asthma and chronic obstructive pulmonary disease, it is possible for pharmacy cost to decrease with higher adherence because of improved symptoms control and lung function, leading to reduced use of additional drugs from complications (eg, oral steroids, antibiotics). ${ }^{32,33}$ For other conditions such as diabetes, hypertension, and hypercholesterolemia, research has demonstrated the association of higher adherence with improved clinical outcomes, ${ }^{17-19}$ which also could lead to decreased use of additional medications and lower pharmacy cost.

It is important to note that several limitations exist in the present study. First, adherence was measured based on pharmacy claims data, which only show that a prescription was filled. It is unknown whether the prescription was taken as prescribed, which by definition is adherence. Second, the PMTX+ database used to assess the outcomes and predictors of interest is mostly representative of a commercially insured population, and as such the study findings might not be generalizable to other US insured populations (eg, feefor-service Medicare and Medicaid). Third, as with all nonrandomized observational studies, other unobservable factors have the potential to confound the results of the present study if they were correlated with the outcomes and predictors of interest, to the extent that such factors could not be assessed within the PMTX+ database. Fourth, patients with multiple comorbidities may have been utilizing medications for other conditions before initiating therapy under any of the drug classes of interest in the present study. As such, the timing of the estimated impacts of adherence could be accumulative, spanning longer than the 6-month period specified in the analysis. Lastly, this study assesses the overall impact of a multifaceted set of interventions and does not measure the incremental impact of individual programs. Previous studies have examined the impact of reminder systems ${ }^{34-36}$ and pharmacist counseling for patients new to therapy. ${ }^{14}$ Further research is recommended to examine the incremental impact of individual interventions within different drug classes.

\section{Conclusion}

A community pharmacy's multifaceted set of adherence interventions were associated with patients having significantly higher medication adherence and lower health care utilization and costs within a commercial population. The study findings are consistent with those of other studies demonstrating the impact of pharmacy-driven interventions on medication adherence and patient outcomes. ${ }^{14,37,38}$ Modifiable patient factors demonstrated to be associated with nonadherence to medications include knowledge, attitudes, or medication beliefs, ${ }^{20,21}$ forgetfulness, ${ }^{22,23,39}$ and lack of medication self-efficacy. ${ }^{40,41}$ The community pharmacy's interventions were carefully designed and implemented to address these factors, and to provide support for patients throughout their chronic conditions management journey.
Overall, this study demonstrates how a community pharmacy can help payers improve population health and help manage total health care costs. Given the study findings, payers and patients should consider participating in comprehensive adherence programs that include counseling, reminders, and the opportunity to engage in multiple regular interactions with pharmacists to improve medication adherence.

\section{Author Disclosure Statement}

Drs. Akinbosoye, Taitel, Grana, and Hill, and Mr. Wade declared the following potential conflicts of interest with respect to the research, authorship, and/or publication of this article: All authors are either salaried employees of Walgreen Co. or paid research consultants for the study.

The authors received the following financial support: This study was funded by Walgreen Co.

\section{Acknowledgments}

The authors wish to acknowledge Heather Kirkham, PhD, MPH, Bobby Clark, PhD, MSPharm, MHA, Heidi Hilker, PharmD, Chet Robson, DO, MHCDS, Ed Cohen, PharmD, Catherine Macpherson, MS, RD, Kainan Sun, PhD, Swapna Karkare, MS, Jenny Jiang, MS, Ying Mu, MS, and Barry Cheung, ASA, for their contributions to study design, analyses, statistical programming, data management, actuarial modeling, and/or manuscript development.

\section{References}

1. Doggrell SA. Adherence to medicines in the older-aged with chronic conditions: does intervention by an allied health professional help? Drugs Aging. 2010;27:239-254.

2. Ho PM, Rumsfeld JS, Masoudi FA, et al. Effect of medication nonadherence on hospitalization and mortality among patients with diabetes mellitus. Arch Intern Med. 2006;166:1836-1841.

3. Kronish IM, Ye S. Adherence to cardiovascular medications: lessons learned and future directions. Prog Cardiovasc Dis. 2013;55:590-600.

4. Burkhart PV, Sabate E. Adherence to long-term therapies: evidence for action. J Nurs Scholarsh. 2003;35:207.

5. Roebuck MC, Liberman JN, Gemmill-Toyama M, Brennan TA. Medication adherence leads to lower health care use and costs despite increased drug spending. Health Aff. (Millwood). 2011;30:91-99.

6. Toy EL, Beaulieu NU, McHale JM, et al. Treatment of COPD: relationships between daily dosing frequency, adherence, resource use, and costs. Respir. Med. 2011;105: 435-441.

7. Pittman DG, Tao Z, Chen W, Stettin GD. Antihypertensive medication adherence and subsequent healthcare utilization and costs. Am J Manag Care. 2010;16:568-576.

8. Zwikker HE, van den Bemt BJ, Vriezekolk JE, van den Ende $\mathrm{CH}$, van Dulmen S. Psychosocial predictors of nonadherence to chronic medication: systematic review of longitudinal studies. Patient Prefer Adherence. 2014;8:519-563.

9. Bosworth HB, Granger BB, Mendys P, et al. Medication adherence: a call for action. Am Heart J. 2011;162:412-424.

10. Krueger KP, Berger BA, Felkey B. Medication adherence and persistence: a comprehensive review. Adv. Ther. 2005; 22:313-356.

11. Iuga AO, McGuire MJ. Adherence and health care costs. Risk Manag Healthc Policy. 2014;7:35-44. 
12. Lawrence DB, Allison W, Chen JC, Demand M. Improving medication adherence with a targeted, technology-driven disease management intervention. Dis Manag. 2008;11: 141-144.

13. Murray MD, Young J, Hoke S, et al. Pharmacist intervention to improve medication adherence in heart failure: a randomized trial. Ann. Intern. Med. 2007;146:714-725.

14. Taitel M, Jiang J, Rudkin K, Ewing S, Duncan I. The impact of pharmacist face-to-face counseling to improve medication adherence among patients initiating statin therapy. Patient Prefer Adherence. 2012;6:323-329.

15. Brown MT, Bussell JK. Medication adherence: WHO cares? Mayo Clinic Proc. 2011;86:304-314.

16. Osterberg L, Blaschke T. Adherence to medication. N Engl J Med. 2005;353:487-497.

17. Stewart K, George J, Mc Namara KP, et al. A multifaceted pharmacist intervention to improve antihypertensive adherence: a cluster-randomized, controlled trial (HAPPy trial). J Clin Pharm Ther. 2014;39:527-534.

18. Altowaijri A, Phillips CJ, Fitzsimmons D. A systematic review of the clinical and economic effectiveness of clinical pharmacist intervention in secondary prevention of cardiovascular disease. J Manag Care Pharm. 2013;19:408-416.

19. Chisholm-Burns MA, Kim Lee J, Spivey CA, et al. US pharmacists' effect as team members on patient care: systematic review and meta-analyses. Med Care. 2010;48: 923-933.

20. Gujral G, Winckel K, Nissen LM, Cottrell WN. Impact of community pharmacist intervention discussing patients' beliefs to improve medication adherence. Int J Clin Pharm. 2014;36:1048-1058.

21. Zwikker HE, van den Ende $\mathrm{CH}$, van Lankveld WG, et al. Effectiveness of a group-based intervention to change medication beliefs and improve medication adherence in patients with rheumatoid arthritis: a randomized controlled trial. Patient Educ. Couns. 2014;94:356-361.

22. Ekedahl A, Oskarsson V, Sundberg B, Gustafsson V, Lundberg T, Gullberg B. Impact of postal and telephone reminders on pick-up rates of unclaimed e-prescriptions. Pharm World Sci. 2008;30:503-508.

23. Vervloet M, Linn AJ, van Weert JC, de Bakker DH, Bouvy ML, van Dijk L. The effectiveness of interventions using electronic reminders to improve adherence to chronic medication: a systematic review of the literature. J Am Med Inform Assoc. 2012;19:696-704.

24. Sullivan GM, Feinn R. Using effect size-or why the P value is not enough. $\mathrm{J}$ Grad Med Educ. 2012;4:279-282.

25. Cramer JA, Benedict A, Muszbek N, Keskinaslan A, Khan ZM. The significance of compliance and persistence in the treatment of diabetes, hypertension and dyslipidaemia: a review. Int J Clin Pract. 2008;62(1):76-87.

26. Rubin DB, Thomas N. Combining propensity score matching with additional adjustments for prognostic covariates. J Am Stat Assoc. 2000;95(450):573-585.

27. Hanley JA, Negassa A, Edwardes MD, Forrester JE. Statistical analysis of correlated data using generalized estimating equations: an orientation. Am J Epidemiol. 2003; $157: 364-375$
28. Ballinger GA. Using generalized estimating equations for longitudinal data analysis. Organ Res Meth. 2004;7:127-150.

29. Zorn C. Comparing GEE and robust standard errors for conditionally dependent data. Political Research Quarterly. 2006;59:329-341.

30. Kane S, Shaya F. Medication non-adherence is associated with increased medical health care costs. Dig. Dis. Sci. 2008;53:1020-1024.

31. Zhong W, Maradit-Kremers H, St Sauver JL, et al. Age and sex patterns of drug prescribing in a defined American population. Mayo Clin Proc. 2013;88:697-707.

32. Menzin J, Boulanger L, Marton J, et al. The economic burden of chronic obstructive pulmonary disease (COPD) in a U.S. Medicare population. Respir Med. 2008;102:1248-1256.

33. Restrepo RD, Alvarez MT, Wittnebel LD, et al. Medication adherence issues in patients treated for COPD. Int J Chron Obstruct Pulmon Dis. 2008;3:371-384.

34. Mu Y, Rudkin K, Lou Y, Ewing S, Taitel M. Impact of automated telephonic reminders on patient on-time medication refills: initial findings of a randomized study. Value Health. 2013;3(16):A33.

35. Mu Y, Rudkin K, Taitel M. Effectiveness of automated telephonic reminders on medication adherence. Value Health. 2012;15(4):A23.

36. Taitel M, Mu Y, Lou Y, Cannon A. Impact of email refill reminders on medication adherence among patients with chronic diseases in a retail community pharmacy. Value Health. 2015;18(3):A259-A260.

37. Farsaei S, Sabzghabaee AM, Zargarzadeh AH, Amini M. Effect of pharmacist-led patient education on glycemic control of type 2 diabetics: a randomized controlled trial. J Res Med Sci. 2011;16(1):43-49.

38. Heisler M, Hofer TP, Schmittdiel JA, et al. Improving blood pressure control through a clinical pharmacist outreach program in diabetes patients in two-high performing health systems: the Adherence and Intensification of Medications (AIM) Cluster Randomized Controlled Pragmatic Trial. Circulation. 2012;125:2863-2872.

39. Reidel K, Tamblyn R, Patel V, Huang A. Pilot study of an interactive voice response system to improve medication refill compliance. BMC Med Inform Decis Mak. 2008;8:46.

40. Schoenthaler A, Ogedegbe G, Allegrante JP. Self-efficacy mediates the relationship between depressive symptoms and medication adherence among hypertensive African Americans. Health Educ Behav. 2009;36:127-137.

41. Barclay TR, Hinkin CH, Castellon SA, et al. Age-associated predictors of medication adherence in HIV-positive adults: health beliefs, self-efficacy, and neurocognitive status. Health Psychol. 2007;26:40-49.

Address correspondence to: Michael S. Taitel, PhD Walgreen Co. 1415 Lake Cook Road, MS\#L444 Deerfield, IL 60015

E-mail: michael.taitel@walgreens.com 